\title{
Vegetables at Any Cost: How the Media Markets Children's Unhealthy Food Preferences in North America
}

\author{
Meghan Lynch
}

Published online: 7 August 2011

(C) Springer Science+Business Media, LLC 2011

\begin{abstract}
This editorial explores the recent endorsement by the North American media of blending, or 'disguising,' vegetables in other foods as a strategy for encouraging children to eat vegetables. The author argues that the myriad of media such as books, television programs, and internet sites that promote diverse, and often inconsistent, advice on children's nutrition contributes to the challenge, rather than aids, parents and teachers in successfully encouraging children to develop healthy food preferences. In this editorial, a sample of media promoting the disguising vegetable strategy are presented and compared to research recommendations for children's healthy food preference development. To promote this strategy, the media were found to draw upon a variety of authority sources and stress the necessity of young children eating adequate servings of vegetables. Such advice was found to contrast with research recommendations for developing children's long-term healthy nutritional behaviours. In light of such findings, the editorial concludes with recommending areas needed for future research and practice.
\end{abstract}

Keywords Young children - Food preferences - Media · Social factors

It is well-established that children who are introduced to a healthy and varied diet early in life have the best chance of developing healthy food preferences throughout their lives (Aldridge et al. 2009; Liem and Menella 2002). For instance, Skinner et al. (2002) found that children who

M. Lynch $(\bowtie)$

Dalla Lana School of Public Health, University of Toronto,

155 College Street, Toronto, ON M5T 3M7, Canada

e-mail: meghan.lynch@utoronto.ca were exposed to a wide variety of fruits and vegetables in their first years of life preferred these foods later in life; the most significant predictor of a child's food preferences at age eight was the child's food preferences at age four. Unfortunately, translating research on fostering healthy food preferences into approaches parents, teachers, and childcare providers (who will be collectively be referred to as 'parents' for the remainder of this editorial) are willing and able to use has proven to be a challenge (Carruth et al. 2004). In this editorial, I question the strategy of blending —or 'disguising' - vegetables into other foods, as opposed to repeatedly presenting children with the vegetables, promoted by a variety of media such as cookbooks, television programs, and internet sites. With the ultimate objective of parents being portrayed as ensuring their children consume adequate vegetable servings, parents are encouraged to adopt any means necessary to achieve this goal.

At the forefront of this disguising vegetable movement are instructive cookbooks that depict mealtime as the preeminent moment for children's future health. For example, in Sneaky Veggies: How to get vegetables under the radar and into your family (Fisk 2006) parents are informed from the outset that "Your mission, should you choose to accept it, is to feed your children well, whether they know it or not!" because "Nobody wants to do battle with the ones they love" (p. 7). Parents are greeted with an even more alarming message from another author who warns: "Do you want your kids to be among the nine million children who are overweight or obese? Children have enough to deal with when they're growing up without being saddled with a whole host of additional problems" (Lapine 2007a, p. 26). Similar themes introduce The Art of Hiding Vegetables: Sneaky Ways to Feed Your Children Healthy Food (Bali and Child 2010) and Raising Healthy Eaters: 100 
Tips For Parents (Legere 2009), which includes as "Tip 43: Camouflage vegetables in foods your kids will eat... Try hiding vegetables in foods they will eat. In this case, what your kids know won't hurt them. In fact, it'll be good for them" (p. 61). Two parenting cookbooks stand apart from the rest as best-sellers that have garnered the most attention: Deceptively Delicious: Simple Secrets to Get Your Kids Eating Good Food (Seinfeld 2007) and The Sneaky Chef: Simple Strategies for Hiding Healthy Foods in Kids' Favorite Meals (Lapine 2007a). These books have become popular topics on television programs, with authors appearing and being endorsed on such television programs as Oprah Winfrey, The Today Show, The Doctors, and $A B C$ News. In fact, the Oprah Winfrey website actually includes an entire section devoted to this topic and written by Seinfeld (Oprah.com 2007). Not only are these books been endorsed by media authorities, but the authors have also drawn upon the authority of selective research and medical establishments to further develop the legitimacy of their strategy. The foreword in Lapine's (2007a) book was written by physician and professor of clinical paediatrics Anastassios Koumbourlis, who emphatically supports the disguising vegetable strategy because it "offers a pragmatic way to enrich their [children's] culinary experiences by bypassing their own negative perceptions. Eventually, they may be persuaded to actually try the food without disguises... With any luck, they may even like it" (p. 17). Importantly, while pages later Lapine acknowledges that offering children multiple exposures to new foods is the recommended method for developing children's healthy nutritional behaviours, she is quick to withdraw such a suggestion by stating, "Who has that kind of time or tenacity?" (2007a, p. 25). Moreover, to further justify the disguising vegetable strategy, Lapine (2007b) frequently draws upon the authority of research by Leahy et al. (2008). This study used an experimental design to compare the caloric consumption of two groups of children who ate pasta with either vegetables blended into the sauce or sauce without vegetables blended in. They concluded that the group that consumed the sauce with the vegetables blended in —not surprisingly—consumed more vegetables and reduced their calorie consumption significantly compared to children who ate pasta without vegetables blended in. Lapine (2007b) contends the study validates her technique, declaring it provides "compelling proof that the 'sneaking technique' really works. The vegetables that children used to resist, they will now eat without a fight, and their bodies will prosper because of it. Sneaking is proving itself to be a highly effective way to get kids to consume more from the healthier food groups and less from the undesirable foods, like fats and sugars." Perhaps even more surprising are her claims that "The only real difference between the study and the book is that the book picks up where the study leaves off. The purpose of the study is to tell parents what to do. It doesn't tell them how. In my book, I present a dozen creative methods for sneaking superfoods into meals that kids will actually eat without a fight" (Lapine 2007b). Yet, despite Lapine's assertions, Leahy et al.'s (2008) study was limited in not being used in a real-world situation, a significant limitation, given the challenges in translating lab-based research into techniques parents can actually employ. For example, I would argue that blending vegetables would obviously require more time and effort in mealtime preparation. Additionally, being cross-sectional, the study is limited in not being able to determine how such a strategy impacts children's long-term dietary preferences. Thus, while future research may further Leahy et al.'s (2008) findings, I find it difficult to accept that this preliminary study proves anything more than simply showing that adding vegetables to pasta sauce provides children with more vegetables than not adding them. However, the bold claims made by Lapine (2007b) certainly do deserve attention by those concerned with what is being promoted to parents as healthy ways to develop healthy long-term behaviours in children.

In addition to the more traditional media of books and television, I was interested to see how the internet provides another medium to promote the disguising vegetable strategy, particularly, given that recent research has revealed that the internet is a popular tool for acquiring health information (Banas 2008; Dart 2008). Not surprisingly, online parenting sites promote this strategy similarly, in some instances, even including the same authors as those previously described. For instance, online articles advocating for disguising vegetables penned by Lapine on canadianparents.com include Keeping one step ahead of your picky eaters as well as How to avoid kids' blood sugar spike and crash. Articles on other sites provide similar advice, such as on parentscanada.com which includes the article How to include greens in your kids' meals, where the disguising vegetable strategy was tested: "We snuck some into unsuspecting foods and chose a panel of nonveggie eaters to give them a try" (van Rosendaal 2007). The sites, much like the cookbooks, draw upon a variety of authority sources. On parents.com a dietician advises parents in the article Sneak in some veggies (Wiener 2010) that "Everything tastes better when it's doused in cheese!" Noteworthy, this article similarly drew upon the study by Leahy et al. (2008) for proving the success of the disguising vegetable strategy, as they explicitly advocated for parents to use "stealth vegetables." Likewise, the article on Foodnetwork.com Tips for kid-friendly vegetable dishes advocates parents "Try burying healthy foods in breads and muffins ... a great "hiding" spot for carrots or zucchini" and "Puree vegetables into pasta sauces. If your child craves pasta for every meal, don't panic. Just use the 
blender or food processor to puree broccoli or peppers (a great source of vitamin $\mathrm{C}$ ) and carrots and spinach (for a blast of vitamin A) to add to tomato and other sauces... If you've got a mac and cheese lover, mash some steamed cauliflower into the cheese sauce for extra nutrients." Finally, parenting articles on About.com promote similar advice in Sneaking vegetables into your kids' meals (Keith). Interestingly, the author of this article, unlike the past authors, does not draw upon authority sources to legitimize the strategy, but instead relates to parents by stating, "I wish I knew the secret of parents whose kids love vegetables. We tried everything to get ours to learn to love their vegetables, but we were never really successful. If you need to find ways to get vegetables into your picky eater's diet while they are developing their taste for healthy foods, try these ideas" (Keith).

As I hope this sample of media shows, by drawing upon both language that stresses the urgency of ensuring children eat the recommended servings of vegetables, and citing a variety of authority sources, these media sources promote this strategy as an unquestionably ratified way for parents to introduce vegetables to their children. While this movement has not been without its critics, discussions tend to focus on the dishonesty involved in "sneaking" healthy foods into children's meals, and how children will feel deceived and distrust their parents when they find out how the foods are being prepared (Helm 2007), rather than on the possible long-term consequences such a strategy could have on children's nutritional behaviours.

\section{What is Wrong with Disguising Vegetables?}

While I am not suggesting that the above section represents a comprehensive survey of all the nutritional advice available to parents, as can be seen by the media examples from books, television programs, and internet sites, it is clear that the authors promoting this feeding strategy use a savvy strategy of drawing upon parents' fears, celebrities, selective research, and medical professionals. Unfortunately, though the media may describe this strategy as appropriate, I contend that this disguising vegetable strategy is contradictory to what research has found is needed to develop children's lifelong food preferences for healthy foods (Aldridge et al. 2009; Birch 1998, 1999; Cooke 2007). Consequently, while the authors may claim that concealing vegetables in pasta sauce is an effective strategy for increasing children's vegetable intake, this practice does not enable children to become familiarized with the vegetable, and thus in the long run, is questionable, at best, for encouraging the development of lifelong healthy food preferences (Birch 1999; Cooke 2007; Johnson 2000).
Childhood is a significant critical period for the formation of food preferences (Cashdan 1994; Hendy 1999). An understanding of children's food neophobia is an important concept to appreciate for why disguising vegetables only presents a short-term solution that may in fact do more harm than good in the long run. Food neophobia is a predisposition children have for avoiding new foods that has been suggested to serve as a protective mechanism (Birch 1999). The strength of children's neophobic response to food changes during development; for example, after infancy, neophobia may be more persistent with preschool children. That being said, there is evidence for familial similarities in neophobia, and this cannot be attributed (at least entirely) to genetics (Birch 1999). Parents project their own food preferences onto children (Mata et al. 2007) and there is a very strong affective aspect to food preferences; children learn what to like, dislike, disgust, etc. (Birch 1990, 1999).

Consequently, it is essential to teach parents that children's initial rejections of new foods do not represent innate food preferences, but transient reactions that can be changed and developed through learning and experience (Birch 1998). For example, children's initial rejections of new foods can be overcome by providing them with many opportunities to taste the foods (Sullivan and Birch 1990), and repeatedly presenting a food in a positive context results in increased liking for that food (Birch 1998). What this suggests is that children's food preference formation is linked with their familiarity with foods during early childhood-the more familiar the food, the more it is liked (Birch and Marlin 1982; Cooke 2007). Familiarity is achieved through exposure to foods with experience playing a significant role in developing preferences. Visual familiarity is described as a key concept in children's decision to try a novel food, as children prefer foods that they frequently see in their environments (Story et al. 2002). It should follow, then, that one of the most important ways parents can encourage the development of healthy food preferences is by increasing children's familiarity with new foods. As can be seen, unlike what is being promoted through the media, research recommends the need for more nutrition interventions that focus on increasing familiarity, rather than disguising, healthy foods (Cooke and Wardle 2005).

Despite these findings, parents typically use strategies such as the disguising vegetable technique that are effective in achieving short-term goals (such as the children eating fruits or vegetables) but are counterproductive to building desirable long-term behaviours (Johnson 2000). What this means is that while developing a better understanding of children's food preference development is crucial, understanding how to communicate these findings and developing practices parents can actually use is 
perhaps even more crucial. This is much-needed, as research has found that parents are often unwilling or unable to provide their children the 10-20 exposures necessary to familiarize them with new foods (Carruth et al. 2004).

\section{Implications for Research and Practice}

In the following section, I present findings from several novel studies that have presented complementary and successful approaches for reducing children's food neophobia, as opposed to suggesting parents rely solely upon repeatedly offering the foods at mealtimes. While these studies merit replication and further refinement by the research community, they could be promoted to parents as strategies to try at home.

As hinted at earlier, with young children, research on the promotion of children's food preferences suggests using the concept of visual familiarity as an effective strategy for reducing neophobia. Houston-Price et al. (2009) explored how picture books featuring vegetables could be used to encourage children to try new foods. In their study, parents of 20 children aged 21-24 months read a picture book about foods every day for 2 weeks. They found that children who were exposed to vegetables via the picture books had a reduced aversion to unfamiliar foods relative to familiar foods, and an increased willingness to taste exposed foods than non-exposed foods. Importantly, their study occurred in home settings and involved parent-child interactions. Still, this study is limited in being cross-sectional and the researchers did not investigate if the children's eating habits changed at home. Nevertheless, the researchers suggested that visual exposure could reduce the number of exposures needed to increase willingness to eat foods, and that visual exposure impacts on children's willingness to taste foods. Very little research has explored visual exposure as an avenue for promoting food preference development, and thus further research into visual familiarity is much-needed.

Likewise, another unique approach to visually familiarizing children with new foods is through play settings. Parents could use food-themed play settings to foster healthy nutritional behaviours by ensuring that children interact with a variety of healthy toy food replicas (such as fruits and vegetables, grains, and dairy), and through sociodramatic play in toy kitchens, supermarkets, and restaurants, children could also be encouraged to pretend to cook and eat healthy foods. It may be possible through a playbased setting to develop children's familiarity with healthy foods and thus to improve their willingness to consume these foods (Story et al. 2002). Similar to Houston-Price et al.'s (2009) work, further research testing of play-based assessments could prove similarly productive.

An interesting related area of research that could be harnessed to develop children's healthy food preferences explores how children's preferences for foods can be affected by brand preferences. Typically, articles describe taste and texture as being the only factors that influence children's preferences for foods, yet, several studies have found children's preference for certain brands have a strong impact on their preferences for foods. Robinson et al. (2007) examined if children prefer the taste of food if they believe it is from McDonalds. In their study, 63 children aged 3-5 years tasted 5 pairs of identical foods and beverages in packaging and asked to indicate if they thought they tasted the same or if one tasted better. Results revealed significantly higher rating if foods were thought to be from McDonalds. Interestingly, they found the same results (preferring the food if it was packaged in McDonalds wrapping) was found even for carrots - a food that is neither marketed nor available from McDonalds. Likewise, Roberto et al. (2010) studied 40 children aged 4-6 years tasting 3 pairs of identical foods (graham crackers, gummy fruit snacks, and carrots). The foods were presented to the children either packaged in a wrapper with a popular cartoon character on it or not and after tasting both, were asked which food tasted better. In line with the results of Robinson et al. (2007), results showed that the children significantly preferred the taste of foods with popular characters on the packaging. Thus, the authors conclude that branding of foods influences young children's taste perceptions. Both these studies reveal the myriad of factors that are involved in children's liking of food.

Lastly, though conducted with an older group of children, another novel study that examined how to reduce children's neophobic response was by Mustonen and Tuorila (2009). This study examined 164 children aged 8-11 years who participated in the French sensory education program "Classes du gout." The goal of the program was to reduce food neophobia in children and encourage children to try new, unfamiliar foods. The program consisted of taste lessons aim to teach young children to become aware of the quality differences in foods through their sensory experiences, as well as to teach children about the pleasures of food. Lessons were provided to classes at schools, not individual children. The researchers compared the preferences of groups who received the lessons to those who did not. The overall conclusion of the researchers was that sensory education decreased neophobia scores, especially in the younger children. The authors recommend new means should be developed for decreasing children's neophobia.

As all these studies reveal, future research could investigate a variety of strategies for reducing children's 
neophobia, such as whether interacting with toy replicas of healthy foods promotes children's real food-preference development. While many of these studies are preliminary and are in need of future research, much can be gleaned for practice. Familiarizing children with healthy foods through books and toys could prove effective in improving their visual familiarity to healthy foods.

In terms of implications for practice, with all of these suggestions, it is important to communicate to parents that they are intended to complement and not replace offering new foods at meals on multiple occasions. It is also imperative to communicate to parents how they can aid children in developing healthy dietary habits, especially by encouraging them to be less focused on the immediate goal of fruit and vegetable consumption and more on establishing long-term healthy nutritional behaviours. Considering the breadth of media being used to promote the disguising vegetable strategy, it would appear additionally imperative to communicate this information through alternative modes of communication, such as internet parenting sites. By embracing alternative methods for developing children's food familiarity and the new modes of communication available, there will be better chances for the long-term development of children's healthy food preferences.

Acknowledgments This work was funded by the Vanier Graduate Scholarship Program.

\section{References}

Aldridge, V., Dovey, T. M., \& Halford, J. C. J. (2009). The role of familiarity in dietary development. Developmental Review, 29, 32-44.

Bali, K., \& Child, S. (2010). The art of hiding vegetables: Sneaky ways to feed your children healthy food. Great Ambock, GB: White Ladder Press.

Banas, J. (2008). A tailored approach to identifying and addressing college students' online health information literacy. American Journal of Health Education, 39(4), 228-236.

Birch, L. L. (1990). Development of food acceptance patterns. Developmental Psychology, 26(4), 515-519.

Birch, L. L. (1998). Development of food patterns in the first years of life. Proceedings of the Nutrition Society, 57, 617-624.

Birch, L. L. (1999). Development of food preferences. Annual Review of Nutrition, 19, 41-62.

Birch, L. L., \& Marlin, D. W. (1982). I don't like it; I never tried it: Effects of exposure on two-year-old children's food preferences. Appetite, 3, 353-360.

Carruth, B. R., Ziegler, P. J., Gordon, A., \& Barr, S. I. (2004). Prevalence of picky eaters among infants and toddlers and their caregivers' decisions about offering a new food. Journal of the American Dietitians Association, 104(1), S57-S64.

Cashdan, E. (1994). A sensitive period for learning about food. Human Nature, 5(3), 279-291.

Cooke, L. (2007). The importance of exposure for healthy eating in childhood: A review. The Journal of Human Nutrition and Dietetics, 20(4), 294-301.
Cooke, L. J., \& Wardle, J. (2005). Age and gender differences in children's food preferences. British Journal of Nutrition, 93, $741-746$

Dart, J. (2008). The internet as a source of health information in three disparate communities. Australian Health Review, 32(3), $559-569$.

Fisk, C. (2006). Sneaky veggies: How to get vegetables under the radar and into your family. New York, NY: Sterling Publishing.

Foodnetwork.com. Tips for kid-friendly vegetable dishes. Retrieved February 17, 2011 from http://www.foodnetwork.com/recipesand-cooking/tips-for-kid-friendly-vegetable-dishes/index.html.

Helm, J. (2007). ABC News. Does deception belong at the dinner table? Retrieved February 17, 2011 from http://abcnews.go.com/ Health/Diet/story?id=3945963\&page $=1$.

Hendy, H. M. (1999). Comparison of five teacher actions to encourage children's new food acceptance. Annals of Behavioral Medicine, 21(1), 20-26.

Houston-Price, C., Butler, L., \& Shiba, P. (2009). Visual exposure impacts on toddlers' willingness to taste fruits and vegetables. Appetite, 53, 450-453.

Johnson, S. I. (2000). Improving preschoolers' self-regulation. Pediatrics, 106(6), 1429-1435.

Keith, K. L. Sneaking vegetables into your kids' meals. Retrieved February 17, 2011 from http://childparenting.about.com/od/ recipestips/a/kidsveggies.htm.

Lapine, M. (2007a). The sneaky chef. Philadelphia, PA: Running Press.

Lapine, M. (2007b). New study shows merits of hiding healthy foods in kids' meals. Retrieved February 17, 2011 from http://www. articlesbase.com/nutrition-articles/new-study-shows-merits-ofhiding-healthy-foods-in-kids-meals-146087.html.

Lapine, M. Keeping one step ahead of your picky eaters. Retrieved February 17, 2011 from http://www.canadianparents.com/ article/keeping-one-step-ahead-of-your-picky-eaters 7.

Lapine, M. How to avoid kids blood sugar spike and crash. Retrieved February 17, 2011 from http://www.canadianparents.com/article/ how-to-avoid-kids-blood-sugar-spike-and-crash.

Leahy, K. E., Birch, L. L., Fisher, J. O., \& Rolls, B. J. (2008). Reductions in entree energy density increases children's vegetable intake and reduce energy intake. Obesity, 16(7), $1159-1565$.

Legere, H. (2009). Raising healthy eaters: 100 tips for parents. Ebook: Da Capo Press.

Liem, D. G., \& Menella, J. A. (2002). Sweet and sour preferences during childhood: Role of early experience. Developmental Psychobiology, 41(4), 388-395.

Mata, J., Scheibehenne, B., \& Todd, P. M. (2007). Predicting children's meal preferences: How much do parents know? Appetite, 50(2-3), 367-375.

Mustonen, S., \& Tuorila, H. (2009). Sensory education descreases food neophobia score and encourages trying unfamiliar foods in 8-12 year old children. Food Quality and Preference, 21, 353-360.

Oprah.com (2007). Delicious \& nutritious. Retrieved February 17, 2011 from http://www.oprah.com/food/Delicious-Nutritious7.

Roberto, C. A., Baik, J., Harris, J. L., \& Brownell, K. D. (2010). Influence of licensed characters on children's taste and snack preferences. Pediatrics, 126(1), 88-93.

Robinson, T., Borzekowski, D., Matheson, D., \& Kraemer, H. (2007). Effects of fast food branding on young children's taste preferences. Archives of Pediatrics and Adolescent Medicine, 161(8), 792-797.

Seinfeld, J. (2007). Deceptively delicious: Simple secrets to get your kids eating good food. New York, NY: HarperCollins.

Skinner, J. D., Carruth, B. R., Bounds, W., \& Ziegler, P. J. (2002). Children's food preferences: A longitudinal analysis. Journal of the American Dietetic Association, 102(11), 1638-1647. 
Sullivan, S. A., \& Birch, L. L. (1990). Pass the sugar pass the salt: Experience dictates preference. Developmental Psychology, 26, 546-551.

Story, M., Neumark-Sztainer, D., \& French, S. (2002). Individual and environmental influences on adolescent eating behaviors. Journal of the American Dietetic Association, 102(3), S51. van Rosendaal, J. (2007) How to include greens in your kids' meals. Retrieved February 17, 2011 from http://www.parentscanada. com/eating/articles.aspx?listingid $=495$.

Wiener, L. (2010). Sneak in some veggies. Retrieved February 17, 2011 from http://www.parents.com/kids/nutrition/picky-eaters/ sneak-in-veggies/. 